\title{
Comparative Study of the Use of Diltiazem as an Antispasmodic Drug in Coronary Angiography Via the Transradial Approach
}

\author{
José Ronaldo Mont'Alverne Filho, João Alexandre Rezende Assad, Alexandre do Canto Zago, \\ Ricardo Leite Vieira da Costa, Antonio Guarany Mont'Alverne Pierre, Mohamed Hassan Saleh, \\ Rodrigo Barretto, Sérgio Luiz N avarro Braga, Fausto Feres, Amanda Guerra Moraes Rego Sousa, \\ J osé Eduardo Moraes Rego Sousa
}

São Paulo, SP - Brazil

\begin{abstract}
Objective-To evaluate the impact of the use, prior to the procedure, of injectable diltiazem to prevent complications.

Methods - Between September 2000 and July 2001, 50 patients underwent transradial coronary angiography and were randomized to receive placebo (GI) or diltiazem (GII) through a catheter inserted into the radial artery. All patients received isosorbide mononitrate. Ultrasound analyses of the radial artery were performed before examination, 30 minutes afterwards, and 7 days afterwards to evaluate the flow, the diameter, and the artery output.
\end{abstract}

Results - The radial artery diameter of GI was 2.4 \pm $0.5 \mathrm{~mm}$ before the procedure and $2.3 \pm 0.5 \mathrm{~mm}$ after 30 minutes (NS), whereas in GII the diameter was $2.2 \pm 0.3 \mathrm{~mm}$ before the examination and $2.5 \pm 0.4 \mathrm{~mm} 30$ minutes after it $(P<0.001)$. Radial arteryoutput in group 1 was $7.3 \pm 5.12 \mathrm{~mL}$ min before the examination and $6.1 \pm 3.5 \mathrm{~mL} / \mathrm{min} 30$ minutes after the examination (NS), and GII had an increase of $5.9 \pm 2.5 \mathrm{~mL} / \mathrm{min}$ before examination to $9.05 \pm 7.78 \mathrm{~mL} / \mathrm{min}$ after the examination $(P=0.04)$. Complications (spasm, occlusion, and partial obstruction) occurred in 4 patients $(17.4 \%)$ in GI and did not occur in GII $(P=0.04)$.

Conclusion - The study suggests a decrease in vascular complications through the transradial access for coronary angiography with the use of diltiazem as an antispasmodic drug, resulting in the significant increase in the diameter of the radial artery and radial artery output.

Key words: $\quad$ radial, angiography, coronary

Instituto Dante Pazzanese de Cardiologia.

Mailing address: Sergio Luiz Navarro Braga - Instituto Dante Pazzanese de Cardiologia - Av. Dr. Dante Pazzanese, 500 - 12 - 04012-180 - São Paulo, SP E-mail: slnbraga@cardiol.br
Transradial access for percutaneous procedures, either diagnostic ${ }^{1}$ or therapeutic ${ }^{2}$, in the coronary artery is an alternative to the femoral approach particularly in cases of complex peripheral vascular disease and in some patients using anticoagulants, antiplatelets, or fibrinolytic drugs. Although some doctors consider this approach the first choice $^{3,4}$, it is still used as an alternative in most centers ${ }^{5,6}$, partly because of its limitations and complications. The most frequent complications are local bruising, spasms, and radial artery occlusion. Bleeding, brachial artery perforation or dissection, pseudo aneurysm, and arteriovenous fistula are less frequent complications. Heparin use through a proper radial artery sheath decreased the incidence of occlusion from $70 \%$ to the current levels, around $10 \%$. The use of antispasmodic medications has proven efficient in decreasing radial artery spasms, and no reports exist of its influence on occlusion. Thus, the vasodilating drugs are not standardized, many different combinations have proven effective, and, therefore, the use of these drugs varies considerably. The objective of this study was to evaluate the influence of injectable diltiazem on local complications of transradial coronary angiography.

\section{Methods}

Fifty-one patients with an indication for elective transradial coronary angiography were selected. The patient had to have a positive Allen's test and to give written consent to be included in the study. Exclusion criteria were previous radial or brachial coronary angiography, a history of myocardial revascularization, cardiac arrhythmia, ascending aorta aneurysm, valvular disease, congenital cardiopathy, and continuous use of calcium channel blockers. Patients were divided into 2 groups according to double-blind randomization before the beginning of the examination. Patients who received placebo were called group I (GI), and 
patients who received diltiazem were called group II (GII). Drug infusion (placebo or diltiazem) was performed for 2 minutes to avoid hypotension and bradycardia. Both groups also received isosorbide mononitrate through an arterial sheath, which is part of the routine used in transradial coronary angiography at this institution. The study protocol was approved by the Ethical and Research Committee of the Instituto Dante Pazzanese de Cardiologia (Dante Pazzanese Institute of Cardiology).

After randomization, the patient was sent to the Department of Echocardiography and underwent a preliminary ultrasound study of the radial artery. The right radial artery was the option in all cases, and the corresponding region was prepared conventionally for the examination. Local anesthesia was $1 \mathrm{~mL}$ of lidocaine $2 \%$ administered $1 \mathrm{~cm}$ below the styloid process of the radius. The right radial artery was punctured with a puncture needle $\mathrm{n}^{0} 21$, and a 0.018 " guidewire was introduced, followed by a 6 Fr sheath (Cook ${ }^{\mathrm{TM}}$ Co.) 23-cm long with an external diameter of $2.3 \mathrm{~mm}$. After sheath insertion into the artery, 5,000 UI of sodium heparin were administered and a solution of $20 \mathrm{mg}$ of isosorbide mononitrate was added to a placebo or to $25 \mathrm{mg}$ of diltiazem according to the randomization.

During catheterization, a 0.035 " guidewire $260-\mathrm{cm}$ long was positioned in the ascending aorta to exchange the catheters. Our first choice was the Judkins 4 curve for the right coronary artery, Judkins 3.5 curve for the left coronary artery, and a pigtail catheter. We evaluated the procedure duration from the introduction of the sheath until its removal, the number of catheters used, and the complications that occurred during the examination. After the end of the procedure, the sheath was removed slowly and progressively with monumental flow release through the radial artery. After this maneuver, a compression dressing in " $\mathrm{X}$ " was applied and loosened after 30 minutes, and the patient was sent to the Department of Echocardiography again.

An arterial duplex-scan of the right superior limb was performed using a 5- to 8-MHz (General Electric System Five) linear transducer with a suitable vascular protocol by an experienced echocardiographer with no knowledge of the groups studied.

The examinations were performed 30 minutes before, 30 minutes after (post-immediate), and 7 to 10 days after (post-late) the performance of coronary angiography. In each examination, we assessed the patency of the subclavian, axillary, brachial and ulnar arteries. The analysis of the radial artery is made through the calculation of the systolic peak velocity assessed, mean diameter in diastoles by the bi-dimensional (average of 3 measures) and of the minute volume (pulse Doppler). We performed Allen's maneuver during ultrasound analysis prior to the procedure, and we observed retrograde flow in the ulnar artery. Ultrasound findings can be classified into 3 types: (A) absence of stenosis, (B) partial obstruction (stenosis lower than $70 \%$ ), and (C) occlusion.

Homogeneity between groups was evaluated by the chi-square test and Fisher's exact test. Data were expressed in mean \pm SD. Ultrasound data for diameter and radial artery output before, 30 minutes after, and 7 to 10 days after coronary angiography performance were compared between GI and GII by using the paired $t$ test. Statistical significance was considered $\mathrm{P}<0.05$.

\section{Results}

Between September 2000 and July 2001, 51 patients were randomized to receive placebo $(\mathrm{GI}=23)$ or diltiazem $(\mathrm{GII}=27)$ prior to coronary angiography through a radial approach. In 1 case, it was difficult to advance the 0.018 -in guidewire after appropriate radial artery puncture, and the procedure was performed through a femoral access. The 2 groups did not have differences in clinical characteristics (tab. I).

Coronary angiography was successfully performed in the 50 cases analyzed with selective catheterization of the coronary arteries. The examination was performed with 3 catheters in 17 patients $(73.9 \%)$ in GI and in 23 patients $(85.2 \%)$ in GII. Two catheters were used in only 1 patient $(2 \%)$ in GI and in no patient in GII. Four catheters were used in 5 patients from GI $(21.7 \%)$ and 4 patients from GII (14.8\%). No statistically significant difference existed between the groups $(\mathrm{P}=0.35)$ regarding the number of catheters used. The examination period was $23.5 \pm 13.1$ minutes in $\mathrm{GI}$ and $19.88 \pm 8.16$ minutes in GII $(\mathrm{P}=0.23)$. Radial artery spasms occurred in 1 patient $(2 \%)$ from GI, whose procedure was performed with 4 catheters, in 60 minutes, because it had extreme tortuosity in the right subclavian artery (fig. 1). Only 1 patient ( $2 \%$ ) from GI had hypotension after injection of the solution. Accentuated tortuosity of the right subclavian artery was found in 3 patients $(6 \%)$, and this was responsible for excessive prolonging of the time of the procedure in these cases.

Subclavian, axillary, brachial, ulnar, and radial arteries were patent and with a three-phase flow in all cases. Radial artery diameter in GI was $2.39 \pm 0.45 \mathrm{~mm}$ (1.8 to $3.5 \mathrm{~mm}$ ) before coronary angiography, and $2.35 \pm 0.47 \mathrm{~mm}$ (1.6 to $3.51 \mathrm{~mm}$ ) after its end $(\mathrm{P}=0.73)$. Regarding $\mathrm{GII}$, the previous diameter was $2.15 \pm 0.32 \mathrm{~mm}$ ( 1.3 to $3.0 \mathrm{~mm}$ ) and after examination it was $2.46 \pm 0.39 \mathrm{~mm}$ (1.9 to $3.1 \mathrm{~mm}$ ) with $\mathrm{P}<0.0001$ (fig. 2).

\begin{tabular}{|lrcc|}
\hline \multicolumn{4}{|c|}{ Table I - Clinical characteristics of patients (n=50) } \\
\hline & $\begin{array}{c}\text { Group I } \\
(\mathrm{n}=23)\end{array}$ & $\begin{array}{c}\text { Group II } \\
(\mathrm{n}=27)\end{array}$ & $\mathrm{P}$ \\
\hline & $58.6 \pm 9.27$ & $54.7 \pm 9.09$ & 0.13 \\
Age (years) & $18(78.3 \%)$ & $19(70.4 \%)$ & 0.52 \\
Male gender & $28.1 \pm 3.8$ & $27.05 \pm 3.8$ & 0.31 \\
Body mass index & $18(78.3 \%)$ & $17(63 \%)$ & 0.23 \\
Blood hypertension & $4(17.4 \%)$ & $3(11.1 \%)$ & 0.52 \\
Diabetes & $7(30.4 \%)$ & $11(40.7 \%)$ & 0.44 \\
Smoking & $10(43.5 \%)$ & $7(25.9 \%)$ & 0.19 \\
Dyslipidemia & $11(47.8 \%)$ & $13(48.1 \%)$ & 0.9 \\
Familial history of & & & \\
coronary disease & $12(52.2 \%)$ & $17(63 \%)$ & \\
Clinical picture: Stable angina & $5(21.7 \%)$ & $4(14.8 \%)$ & 0.72 \\
\multicolumn{1}{|c}{ Unstable angina } & $6(26.1 \%)$ & $6(22.2 \%)$ & \\
\hline
\end{tabular}




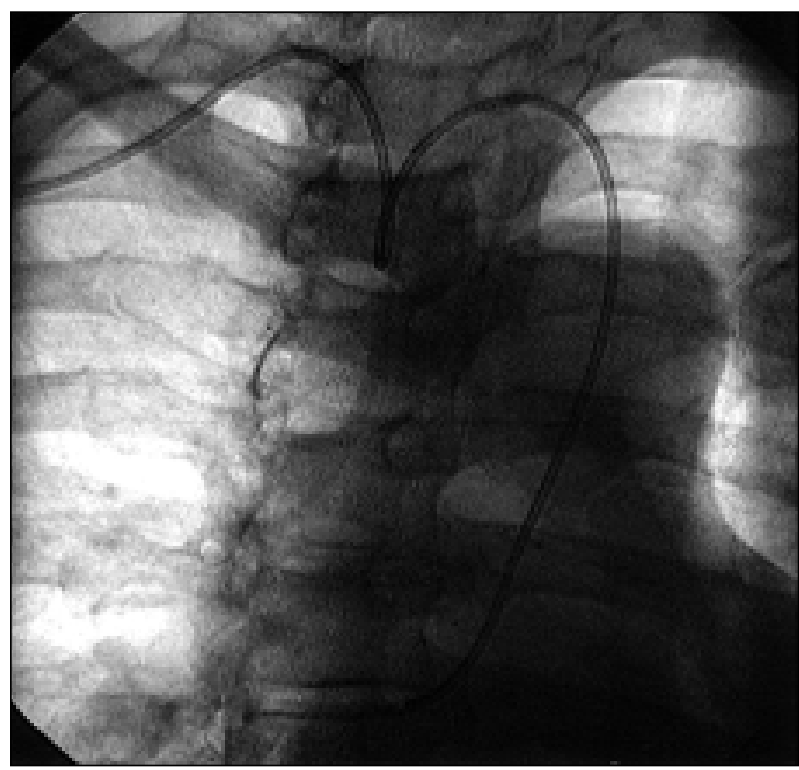

Fig. 1 - Extreme tortuosity in right subclavian artery found in one of the patients justifying greater duration of coronary angiography.

In GI, previous radial artery output was $7.07 \pm 5.37 \mathrm{~mL} /$ $\min (1.65$ to $21 \mathrm{~mL} / \mathrm{min})$, and afterwards it was $5.89 \pm 3.33 \mathrm{~mL} /$ $\min (2.3$ to $12.4 \mathrm{~mL} / \mathrm{min}), \mathrm{P}=0.26$. In GII, output prior to the procedure was $5.74 \pm 2.79 \mathrm{~mL} / \mathrm{min}(1.3$ to $12 \mathrm{~mL} / \mathrm{min})$ and $9.06 \pm 7.78 \mathrm{~mL} / \mathrm{min}$ ( 2.5 to $35.2 \mathrm{~mL} / \mathrm{min}$ ) after coronary angiography, $\mathrm{P}=0.039$ (fig. 3 ). The systolic peak velocity of the radial artery had the same decrease in both groups when compared with previous analyses and analyses preformed 30 minutes after the examination.

Seven days after the performance of coronary angiography, the radial artery diameter observed was $2.41 \pm$ $0.5 \mathrm{~mm}$ in GI and $2.46 \pm 0.42 \mathrm{~mm}$ in GII, and the output was $12.3 \pm 13.47 \mathrm{~mL} / \mathrm{min}$ in GI and $11.9 \pm 12.26 \mathrm{~mL} / \mathrm{Imin}$ in GII, respectively, with no statistically significant difference between the groups.

We observed a slight hematoma in at the site of punc-

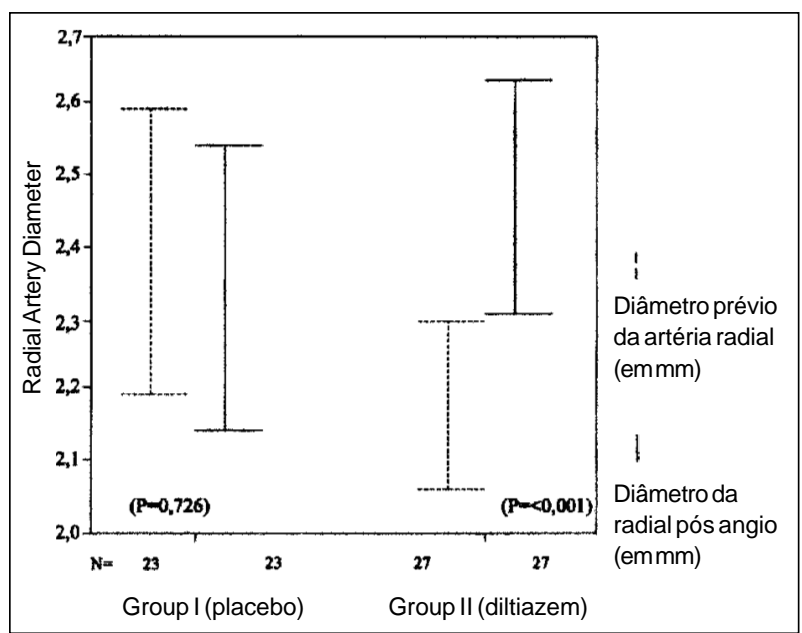

Fig. 2 - Radial artery diameter prior to and 30 minutes after the examination in the 2 groups studied assessed by ultrasound analysis, presenting statistically significant increases in GII (right), which was not observed in GI (to the left).

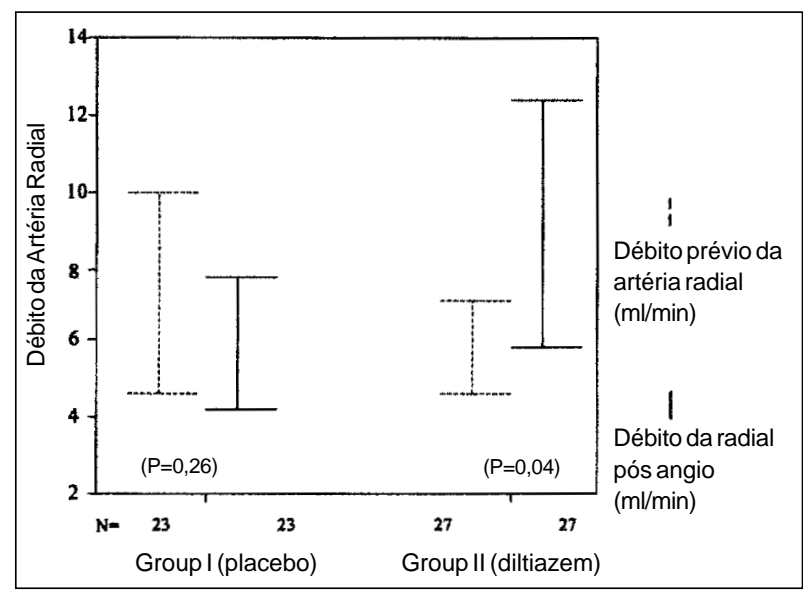

Fig. 3 -Increase in the radial artery output in GII (to the right) compared before and after examination, according to its diameter increase. Such phenomenon is not observed in GI (to the left).

ture in 2 cases ( $4 \%$ ), which healed spontaneously in 3 days, according to the patients, and the hematomas were no longer observed by the echocardiographer after 7 to 10 days. Vascular complications observed in this sample were spasm, occlusion, and partial obstruction of the radial artery (fig. 4), which occurred right after the end of coronary angiography in 4 patients from GI $(17.3 \%)$ but not in patients from GII ( $\mathrm{P}=0.038)$. All patients who experienced complications had prolonged examination times, and in half of the cases, the previous radial artery diameter was smaller than $2.3 \mathrm{~mm}$, referring to the external diameter of the sheath. Complications after 7 to 10 days (occlusion and partial obstruction) occurred in 4 patients from GI $(17.2 \%)$ and not in patient from GII (tab. II). The only case of radial artery occlusion in the analysis performed immediately after the procedure was patent in the later analysis, whereas the case in which the radial artery was occluded in this later analysis, had only flow disturbance, in the analysis performed 30 minutes after the procedure. We did not observe the presence of great
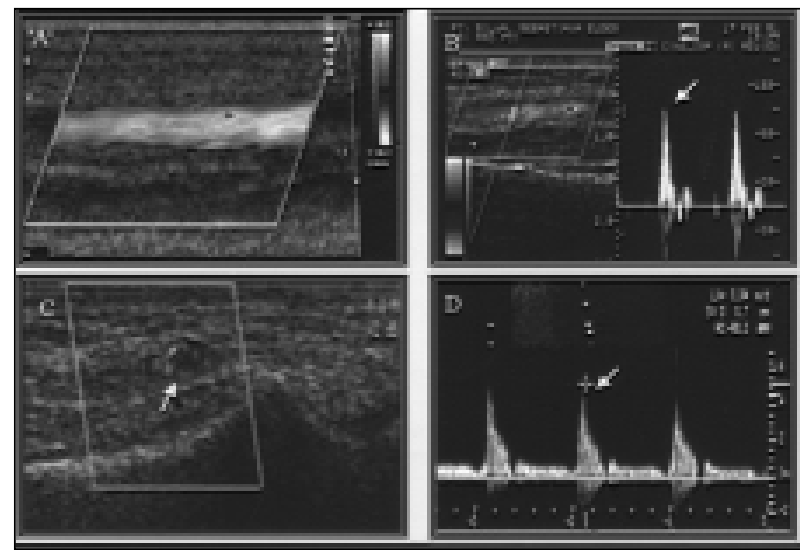

Fig. 4 -A) Bi-dimensional ultrasound image of right radial artery with normal aspect; B) Normal pulsed-Doppler showing three-phase flow with peak systolic velocity $=68 \mathrm{~cm} / \mathrm{s} ;$ C) Bi-dimensional ultrasound imaging of the suboccluded radial artery; D) Altered pulsed- Doppler showing bi-phase flow with increased peak systolic velocity $(506 \mathrm{~cm} / \mathrm{s})$ 


\begin{tabular}{|c|c|c|c|c|}
\hline & \multicolumn{2}{|c|}{ Post-immediate } & \multicolumn{2}{|c|}{ Post-late } \\
\hline & $\begin{array}{c}\text { Group I } \\
(\mathrm{n}=23)\end{array}$ & $\begin{array}{c}\text { Group II } \\
(\mathrm{n}=27)\end{array}$ & $\begin{array}{c}\text { Group I } \\
(\mathrm{n}=23)\end{array}$ & $\begin{array}{c}\text { Group II } \\
(\mathrm{n}=27)\end{array}$ \\
\hline Spasm & $1(4.3 \%)$ & 0 & 0 & 0 \\
\hline Occlusion & $1(4.3 \%)$ & 0 & $1(4.3 \%)$ & 0 \\
\hline Partial obstruction & $2(8.7 \%)$ & 0 & $3(12.9 \%)$ & 0 \\
\hline
\end{tabular}

hematomas or hemorrhaging; therefore, blood transfusion was not necessary in any of the cases.

\section{Discussion}

Transradial access to perform diagnostic procedures, introduced by Campeau ${ }^{1}$ and adapted for therapeutic procedures by Kiemeneij and Laarman ${ }^{2}$ has been progressively used more due to its technological advances, such as in the sheaths, guidewires, and specific catheters but, above all, due to the inherent advantages of the technique. These advantages are its applicability in patients with aortoiliac disease and intense lumbar pain, its enabling of precocious ambulation, the lower hospitalization period with consequent cost reduction, but, especially because it has smaller vascular and hemorrhagic complications then the femoral access has ${ }^{7}$. Radial versus femoral approach studies ${ }^{6,8}$, demonstrated high success rates with the radial access, although this requires a more experienced technician than is necessary with the femoral access, which causes greater local discomfort to the patients longer examination time and exposure to radiation. In the ACCESS ${ }^{9}$ study, transradial access caused fewer vascular complications than did the femoral access ( $2 \%$ versus $0 \%, \mathrm{P}=0.053$ ). A similar result was found by Mann et al ${ }^{10}, 4 \%$ for the femoral access and $0 \%$ for the transradial access $(\mathrm{P}<0.04)$. These advantages of the radial access over the femoral access are more clearly verified in the therapeutic percutaneous procedures, because in these cases, greater doses of heparin are administered during the procedure and, mainly, because of the increasing use of glycoprotein IIb/IIIa inhibitors, especially when acute myocardial infarction and unstable angina are present. Choussat et al, ${ }^{11}$ comparing radial and femoral access for coronary angioplasty with the concomitant use of abciximab, observed much fewer vascular complications with the use of the radial access (hematoma: $3 \%$ femoral $\mathrm{x} 0 \%$ radial; blood transfusion: $1.5 \%$ femoral x $0 \%$ radial; and vascular surgery: $4.4 \%$ femoral $x 0 \%$ radial). Therefore, the safety of the radial access for therapeutic procedures with the use of glycoprotein IIb/IIIa inhibitors exceeds its limitations.

The majority of the transradial technique limitations are radial artery spasm and excessive tortuosity of the subclavian artery, which is more difficult to achieve than aortoiliac tortuosity, hindering the finalization of the procedure through this access ${ }^{12}$. Radial artery spasm was reported by
Hildick-Smith et al ${ }^{5}$ in $10.4 \%$ of patients, and only $2 \%$ needed to change to the femoral access. Vasodilator drugs used in the beginning of the procedure through the sheath to avoid spasm vary considerably, according to the personal experience of each team. Lidocaine use was practically abandoned, so that the "antispasmodic cocktail" is formed by isosorbide mononitrate $(20 \mathrm{mg})$ or isosorbide dinitrate ( 2 to $3 \mathrm{mg}$ ) or nitroglycerin $(250 \mu \mathrm{g}$ ) and verapamil (250 to $500 \mu \mathrm{g})^{5,6,7,13}$. Nevertheless, no other study compared these drugs to others regarding the advantages or disadvantages of one over another, related to decreasing spasm or other vascular complications. Radial artery occlusion, which is generally asymptomatic because the palmar blood flow is supplied effectively by the ulnar artery, is tested before the procedure. This occlusion varies from 6 to $10 \%$ with a recanalization rate after 1 month in 40 to $60 \%$ of the cases ${ }^{14,15}$. Particularly in this evaluation, ultrasound use is of great importance, because clinical pulse evaluation may be misinterpreted by retrograde flow from the ulnar artery ${ }^{16}$. Ultrasound analysis of the radial artery made by Nagai et al ${ }^{13}$ showed $9 \%$ occlusion of the radial artery and $21 \%$ of flow disturbance in the analysis conducted immediately after the procedure. In late analysis, radial artery occlusion was $5 \%$ and flow disturbance was $23 \%$. We observed in this study that some radial arteries that were patent in the analysis conducted right after the procedure, were occluded or had flow disturbances in the later analysis. This study enabled the determination of risk factors for radial artery occlusion: 1) radial diameter before the examination, more relevant when it is $<2 \mathrm{~mm}$; 2) correlation between this diameter and the external diameter of the sheath; and 3 ) diabetes.

In the present study, in the group that used diltiazem, the diameter, considered a risk factor for occlusion, and the radial artery output had a significant increase 30 minutes after the end of the examination, which could justify the smaller complication rate in this group. Factors, such as diabetes, examination duration, and the number of catheters used, are not predictors of complications, corroborating the idea that diltiazem had acted effectively to prevent the complications reported. The limitation of this study is the small number of patients assessed.

In conclusion, this study suggests that the use of diltiazem, as an adjunctive drug to isosorbide mononitrate administered through the transradial sheath, decreases the rate of vascular complications, because it decreases the incidence of spasms and increases the radial artery diameter, with a consequent decrease in its occlusion rate. It is necessary to include a greater number of patients to determine this benefit, so relevant to enhancing the transradial coronary angiography technique.

\section{Acknowledgments}

To Dr. Angela Tavares Paes for cooperation in the statistical analysis of the study and to the Laboratory Baldacci S/A for the support received. 


\section{References}

1. Campeau L. Percutaneous radial artery approach for coronary angiography Cathet Cardiovasc Diagn 1989: 16: 3-7

2. KiemeneijF, Laarman GJ.Percutaneous transradial artery approach for coronary stent implantation. Cathet Cardiovasc Diagn 1993; 30: 173-8.

3. D'Urbano M, Cafiero F. Percutaneous radial approach for coronary angiographv. G Ital Cardiol 1996; 26: 1149-55.

4. Kiemeneij F, Laarman GJ, Slagboom T, et al. Outpatient coronary stent implantation. J Am Coll Cardiol 1997; 29: 323-7.

5. Hildick-Smith DJR, Lowe MD, Walsh JT, et al. Coronary Angiography from the radial artery-experience, complications and limitations. Intern J Cardiol 1998; 64: 231-9

6. Ludman PF, Stephens NG, Harcombe A, et al. Radial versus femoral approach for diagnostic coronary Angiography in stable angina pectoris. Am J Cardiol 1997; 79: $1239-41$.

7. Safian RD, Freed MS. The Manual of Interventional Cardiology. $3^{\text {th }}$ edition. Phisicians' Press, 2001.

8. Louvard Y, Lefevre T, Allaim A, et al. Coronary angiography through the radial or the femoral approach: The CARAFE Study. Cathet Cardiov Interv 2001; 52: 181-7.

9. Kiemeneij F, Laarman GJ, Odekerken D, et al. A randomized comparison of percutaneous transluminal coronary angioplasty by the radial, brachial an femoral approaches: The ACCESS Study. J Am Coll Cardiol 1997; 29: 1269-75.

10. Mann T, Cubeddu C, Bowen J, et al. Stenting in acute coronary syndromes: a comparison of radial versus femoral access sites. J Am Coll Cardiol 1998; 32 572-6.

11. Choussat R, Black A, Bossi A, et al. Efficacy and safety of percutaneous transluminal coronary angioplasty by the radial compared to femoral approaches in patients treated by abciximab. Am J Cardiol 1999; 22: 35P.

12. Kiemeneij F,Laarman GJ, Melker E. Transradial artery coronary angioplasty. Am Heart J 1995; 129: 1-8.

13. Nagai $\mathrm{S}, \mathrm{Abe} \mathrm{S}$, Sato $\mathrm{T}$, et al. Ultrasonic assessment of vascular complications in coronary angioplasty and angioplasty after transradial approach. Am J Cardio 1999; 83: 180-6.

14. Stella P, Kiemeneij F, Laarman G, et al. Incidence and outcome of radial artery occlusion following transradial artery coronary angioplasty. Circulation 1995 92: $1-225$.

15. Byers J, Brown S, Robertson R, et al. Procedural outcome and clinical results after stent deployment from the radial approach. Am J Cardiol 1999; 84: 1088-90.

16. Hall JJ, Arnold AM, Valentine RP, et al. Ultrasound imaging of the radial artery following its use for cardiac catheterization. Am J Cardiol 1996; 77: 108-9.

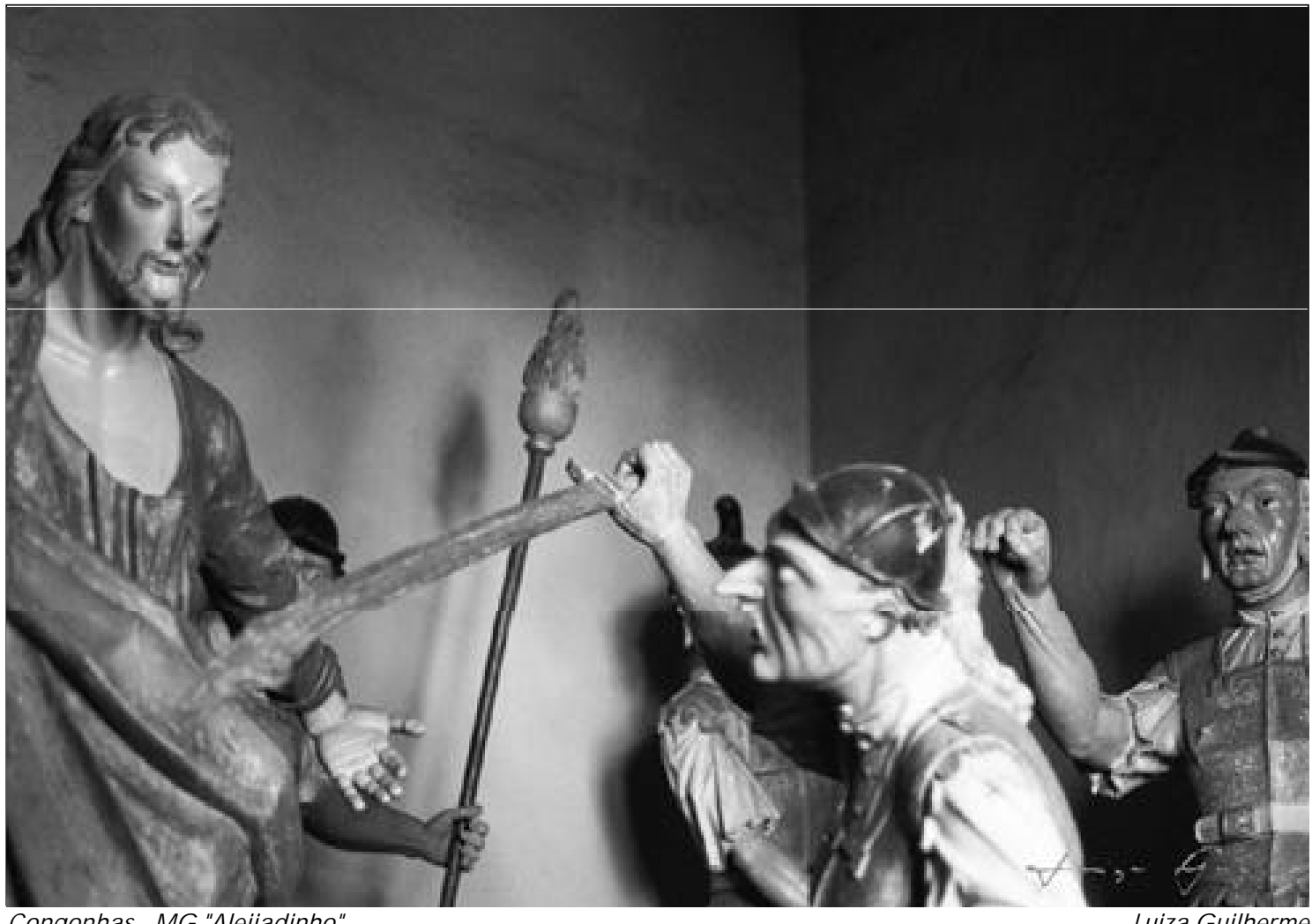

Congonhas - M G "Aleijadinho"

Luiza G uilherme

Editor da Seção de Fotografias Artísticas: Cícero Piva de Albuquerque

Correspondência: InCor - Av. Dr. Enéas C. Aguiar, 44 - 05403-000 - São Paulo, SP - E-mail: delcicero@incor. usp.br 